\title{
POR OUTROS TEXTOS NA SALA DE AULA: ME LEMBRA MUITO PINK FLOYD, DE JOÃO LEOPOLDO
}

\author{
Gustavo NISHIDA ${ }^{1}$ \\ Ana Paula de Castro SIERAKOWSKI ${ }^{2}$
}

\begin{abstract}
Resumo: O objetivo deste trabalho é argumentar em favor da inclusão de outros textos na sala de aula de língua portuguesa. Nossa argumentação aponta para uma expansão no conceito de leitura e para a utilização de outros gêneros discursivos para a formação de leitores. Para tanto, assumimos que, para que o letramento multimodal (ROJO, 2009) chegue à sala de aula, é preciso que outros textos (multimodais e vernaculares) sejam analisados e inseridos no meio educacional. Assim, utilizaremos a canção Me lembra muito Pink Floyd, do compositor paulistano João Leopoldo (faixa do disco Cabeça Madura, de 2010) para exemplificar como a multimodalidade pode figurar na aula de língua materna. Basicamente, a produção de sentido da canção se faz com elementos metalinguísticos da letra que sugerem que essa canção pode parecer com alguma canção do Pink Floyd. Contudo, os elementos musicais não são da banda britânica, são de Imagine, de John Lennon. Em suma, é a integração dos elementos linguísticos e musicais que promove a produção de sentido da canção.
\end{abstract}

Palavras-chave: Multimodalidade. Canção popular. Letramento vernacular.

\section{Introdução}

Em trabalho anterior (NISHIDA, 2013), argumentamos que os letramentos vernaculares (cf. ROJO, 2009) podem servir como a porta de entrada para um letramento dominante. Naquele trabalho, foi mencionado que leituras essencialistas (cf. CORACCINI, 2003) sobre o cânone literário promoviam um olhar dessintonizado com

\footnotetext{
1 UTFPR - Universidade Tecnológica Federal do Paraná - Departamento de Linguagem e Comunicação. Curitiba - Paraná - Brasil. 80230-901 - nishida.utfpr@gmail.com .

2 UNIOESTE - Universidade do Oeste do Paraná - Programa de Pós-Graduação em Letras. Cascavel Paraná - Brasil. 85819-110 - ninhasierakowski@gmail.com

http://dx.doi.org/10.21165/gel.v13i3.1411
} 
as construções de sentidos de interesse do período pós-moderno no qual vivemos. Aqui, assumimos que a canção popular possui uma natureza multimodal e, diante disso, tentamos mostrar que os processos de construção de sentidos devem contemplar tanto os elementos linguísticos (como as letras das canções) quanto os musicais (harmonia e melodia).

Tendo isso em vista, temos como objetivo geral argumentar em favor da inclusão de outros textos na sala de aula de língua portuguesa, tais como os pertencentes ao letramento vernacular (canção popular). Faz-se necessária essa inclusão devido à hegemonia de textos de natureza estritamente escrita e vinculados ao cânone, quase sempre, literário. Para isso, iniciaremos esta reflexão justificando o motivo pelo qual vemos a canção como um objeto interessante para trabalhar com o conceito de multimodalidade. Em seguida, passaremos à análise de uma canção, Me lembra muito Pink Floyd, do artista paulista João Leopoldo, salientando que a produção de sentido está relacionada à integração de aspectos linguísticos e musicais.

\section{Por que a canção?}

Marcuschi (2008) menciona que a adoção do princípio dialógico da linguagem proposto por Bakhtin (1992) ocasionou uma explosão de gêneros para serem trabalhados em aulas de língua materna. Dado esse crescimento exponencial de objetos passíveis de aplicação didática, a simples definição de que a canção é um gênero do discurso faria com que fosse justificado o seu tratamento em ambiente pedagógico. Contudo, preferimos realizar uma breve reflexão para justificar a sua entrada no contexto escolar e, além disso, propor uma maneira de considerá-la a partir da perspectiva da multimodalidade da linguagem.

Primeiramente, é preciso deixar claro que a canção popular sempre fez parte das atividades escolares. Todavia, sua aplicação era justificada principalmente pelo aspecto lúdico, uma vez que a canção tocada em sala de aula quebrava o silêncio imposto pelas práticas escolares tradicionais. Não temos dúvidas de que o aspecto lúdico seja importante. Não estamos criticando esse ponto. Nossa argumentação vai em direção de deixar claro que a simples contemplação de aspectos musicais em sala de aula não garante uma abordagem sintonizada com a concepção de linguagem prevista nas 
diretrizes oficiais de ensino (BRASIL, 1997; PARANÁ, 2008) ou outras propostas teóricas (GERALDI, 1984; ANTUNES, 2001). Por exemplo, a partir de um corpus de análises sobre a canção popular publicado em revistas especializadas em literatura ou música, Costa (2007) menciona que, na maioria dos casos, o tratamento é feito unicamente a partir das letras. Isso mostra que a canção só é utilizada como aspecto lúdico em sala de aula, pois apenas se preferem as letras das canções. Diante disso, perguntamos: do ponto de vista do corpo discente, qual seria a diferença entre ter uma aula sobre um poema ou sobre uma canção sendo que se contempla unicamente a letra da música? Imaginamos que há pouca diferença. Ainda mais quando se vê que, em materiais didáticos, a canção figura ou como uma alternativa ao cânone (como a canção Monte Castelo, da Legião Urbana, com os poemas de Camões) ou como exemplos de linguagem coloquial que, em algum momento, deverá ser "corrigida" em alguma atividade (como as canções de Adoniran Barbosa, por exemplo).

Assumir os gêneros discursivos como materiais pedagógicos é considerá-los em toda a sua materialidade. Em outras palavras, a canção não é só feita de componentes linguísticos, uma vez que fazem parte dela a sua contraparte musical. Diante dessa assunção, só nos cabe assumir que o trabalho com o gênero canção é uma excelente prática para uma abordagem multimodal a fim de que se promova o letramento.

No panorama retratado, fica clara a hegemonia da cultura grafocêntrica nos trabalhos feitos com os gêneros em sala de aula. Gêneros escritos acabam sendo a maioria das escolhas dos professores. Ou porque estão habituados a isso, ou porque não se 'arriscam' a lidar com outros elementos que compõem os sentidos dos textos. Em trabalho anterior (SIERAKOWSKI, 2012), retratamos os argumentos de Kress (2006) em relação ao nosso engajamento com o mundo por meio dos sentidos. Segundo o autor, as sociedades ocidentais letradas primam ainda pelos sentidos que envolvem uma combinação entre o ver e o ouvir, ou seja, o 'ver', relacionado, sobretudo, pela representação gráfica dos sons por meio das letras - a escrita - e o 'ouvir', imbricado aos sons da fala. Na escola, ainda, explora-se majoritariamente o sentido do "ver", ou seja, tudo que está relacionado com a escrita.

Entretanto, essa variedade que nosso corpo tem de se relacionar com o mundo proporciona uma ampla variedade de modos de percepção desse mesmo mundo por meio desses chamados 'sentidos'. Cada um desses sentidos está relacionado de uma 
forma muito específica ao ambiente que nos circunda, provendo-nos informações bem diferenciadas sobre ele (KRESS, 2006). A relação do ser humano com as artes, então, pode ser realizada a partir desses variados modos de 'fruir' um objeto artístico sendo ele imbricado a um ou a vários sentidos. Nesse viés, nenhum desses sentidos age de forma segregada dos outros; eles podem proporcionar a multimodalidade de nosso mundo semiótico. Assim, são as diferentes sociedades as responsáveis por selecionar e desenvolver essas possibilidades de relacionamento com o mundo. Dar primazia apenas para um, ou poucos, desses sentidos, é, de certa maneira, um modo de amputar a 'multimodalidade' das variedades de gêneros que podem ser trabalhados em sala de aula a fim de proporcionar multiletramentos aos alunos.

Além disso, coaduna-se a ideia de Clüver (2007, p. 15, grifo nosso) de que

O repertório que utilizamos no momento da construção ou da interpretação textual compõe-se de elementos textuais de diversas mídias, bem como, frequentemente, também de textos multimídias, mixmídias e intermídias. As comunidades interpretativas, que determinam e autorizam quais códigos e convenções nós ativamos na interpretação textual, influenciam também o repertório textual e o horizonte de expectativas. Mas o repertório é, em última análise, parte dos contextos culturais nos quais se realizam a produção e a recepção textual.

Clüver utiliza o termo de Stanley Fish, comunidades interpretativas, no contexto da recepção de textos além dos escritos, ou seja, textos em outras mídias. Ele afirma que são as comunidades interpretativas responsáveis pela 'autorização' de códigos convenientes para tal sociedade a fim de que tais textos sejam interpretados. É nesse sentido que nos referimos às escolhas prioritárias feitas em sala de aula. Tais escolhas influenciam diretamente no repertório dos receptores (os alunos) de tais textos.

Na nossa sociedade, mesmo diante de várias transformações no que se refere à produção, recepção e circulação dos bens culturais, os textos que se sobrepõem, ainda, em sala de aula, reiteramos, são os escritos, dada a hegemonia da cultura da grafia. Dessa forma, uma visão muito reproduzida é a de que os textos escritos são 'melhores' que os outros e tal fato influencia, também, diretamente no pensarmos 'batido' de que os jovens/alunos não leem, ou apenas leem ou são letrados em textos que não interessam à escola, ou seja, textos que não são apenas escritos, mas que interrelacionam outras mídias, como os textos audiovisuais, por exemplo. Diante dessa 
visão, a recepção de outros tipos de textos parece continuar condicionada à recepção de textos escritos, na eterna afirmação de que o escrito é superior aos outros. Traços desse pensamento estão imbricados ao pensamento de que as outras mídias são meros objetos que podem ajudar o leitor/receptor a galgar o grau maior que é a leitura do texto escrito - normalmente, o cânone literário. Esse pensamento é recorrente e se reproduz, principalmente, em agências legitimadoras do saber - a escola e a universidade como os maiores exemplos.

Antes de simplesmente assumir essa perspectiva teórica, se faz necessário mencionar que o uso de canções, propagandas, vídeo clipes, filmes, seriados (e outros gêneros) está previsto no programa de uma teoria que propõe o multiletramento (ou letramentos - cf. Rojo, 2009). Para considerar o termo no plural, a autora menciona que é possível prever a existência de pelo menos dois tipos de letramento: os dominantes e os vernaculares. Os primeiros seriam aqueles já conhecidos de longa data no ambiente escolar e são regulamentados pelas agências de organização formal da sociedade. A escola, as igrejas, o local de trabalho ou o sistema legal seriam esses espaços (as agências de letramento, segundo Kleiman, 1995) que legitimariam tais práticas letradas e apresentam agentes letradores como professores, padres e pastores, especialistas, pesquisadores, juízes e advogados, por exemplo. É preciso dizer que esses letramentos são dominantes não por serem superiores, mas porque tais conhecimentos são valorizados de maneira ampla dentro da sociedade. Em contrapartida, os letramentos vernaculares não são organizados ou regulamentados por instituições sociais reconhecidas amplamente na sociedade. Elas têm sua origem nas relações cotidianas, nas chamadas culturas locais.

Considerando o mundo contemporâneo, em que, por meio da globalização, nosso contato com a informação é muito maior, Rojo (2009, p.105) afirma ainda que "o surgimento e a ampliação contínua de acesso às tecnologias digitais da comunicação e da informação" (laptops, smartphones, smartTvs, etc.) implicaram em importantes mudanças a respeito da reflexão acerca dos letramentos: a vertiginosa circulação de informação (meios analógicos, digitais, impressos - em menor grau) gerou significativas mudanças nas maneiras de ler, produzir e circular textos nas sociedades; a diminuição das distâncias espaciais desenraizam populações e descontroem identidades; a diminuição das distâncias temporais também colaboram para as mudanças das práticas 
sociais; e a multiplicidade de modos de significar que o texto eletrônico proporciona devem ser consideradas (ROJO, 2009). Diante disso, será que a escola acompanhou essas mudanças? De acordo com Hamilton (2002 apud ROJO, 2009), mesmo que haja muitos letramentos que influenciam e que são valorizados no cotidiano das pessoas, pois têm ampla circulação entre elas, tais letramentos são ignorados e desvalorizados pelas instituições educacionais, pois não são vistos como letramentos 'verdadeiros', legítimos. Vive-se o contraponto entre a realidade das práticas sociais cotidianas e a sua desvalorização/negligência pelas agências do saber.

Seguindo essa visão da autora, propomos aqui que sejam considerados não apenas os letramentos dominantes, mas sim os vernaculares no ambiente escolar, uma vez que:

Cabe, portanto, também à escola potencializar o diálogo multicultural, trazendo para dentro de seus muros não somente a cultura valorizada, dominante, canônica, mas também as culturas locais e populares e a cultura de massa, para torná-las vozes de um diálogo, objetos de estudo e crítica. Para tal, é preciso que a escola se interesse por e admita as culturas locais de alunos e professores (ROJO, 2009, p. 115).

Pensamos que trabalhar com os letramentos vernaculares na escola não é um modo de 'facilitar', pasteurizar a língua materna para os alunos. Acreditamos que trazer essas diferentes manifestações culturais é uma forma de preparar o aluno para ser o tão sonhado 'aluno crítico' e autônomo. Trabalhar com os mais variados letramentos é, como diz Rojo, uma maneira de proporcionar diálogos entre diferentes formas de manifestação artística.

Além de privilegiar as chamadas culturas locais, os gêneros que pertencem aos domínios do letramento vernacular (tal como a canção) podem fomentar uma perspectiva multimodal dentro da sala de aula. Realizar a análise de uma canção levando em conta toda a sua materialidade (letra e aspectos musicais) e ainda buscar outras análises em seus vídeos de divulgação (como vídeos promocionais e vídeo clipes) pode ampliar as análises e possibilitar a formação de um leitor atento a todas essas mídias às quais é exposto a todo momento.

O objetivo aqui é apresentar uma análise ainda preliminar de uma canção que integra material linguístico e o musical. Para tanto, trataremos da canção Me lembra 
muito Pink Floyd, do cantor e compositor paulistano João Leopoldo. Passamos a ela na próxima seção.

\section{Análise}

João Leopoldo é compositor e pianista. Natural de São Paulo, vive atualmente em Sorocaba (SP). O que chama atenção na obra do artista é a sua estética autoral que experimenta a interface com outras artes (como a visual e a narrativa literária) e a sua temática que beira o surrealismo. Além disso, há ampla divulgação de vídeos feitos exclusivamente para a sua difusão nos meios digitais (como seu canal no YouTube ${ }^{3}$ ), que impressionam pela precisão na reprodução e performance das peças musicais todas quase sempre com piano e voz.

Ao contrário do que alguns podem pensar, a sua trajetória artística já beira uma década e conta com 5 discos e dois EP's produzidos de forma independente, chegando a ser bem recebido pela crítica e destaque na mídia nacional através do selo TramaVirtual. Além disso, o compositor ganhou diversos prêmios em festivais, tais como o de melhor composição no Mapa Cultural Paulista de 1998 e em 2000 e a primeira colocação no Festival Nacional de Música de Sorocaba (2008). Ainda cabem destaque as participações (em 2009, 2010, 2015 e 2016) no maior festival de canção do país, o Festival de Música Cidade Canção (FEMUCIC), realizado pelo SESC de Maringá-PR.

Antes de encerrar essa breve apresentação, vale mencionar que João Leopoldo também realiza, em paralelo a seu trabalho autoral, o resgate de grandes artistas brasileiros. No ano de 2014, viajou por Brasília (DF), Salvador (BA) e Recife (PE) com o show "Dolores in Blues". Esse espetáculo foi contemplado pela Caixa Cultural e consistia em versões blues e jazz do repertório da cantora Dolores Duran. Nessa pequena turnê, o artista era acompanhado por banda e pela cantora paulista Paula Cavalciuk.

Tendo realizado essa apresentação do artista, passaremos para análise da canção Me lembra muito Pink Floyd ${ }^{4}$, faixa que abre o disco "Cabeça Madura” (2010). Antes

\footnotetext{
3 Disponível em: <https://www.youtube.com/user/joaoleopoldo/featured>.

4 Para conferir a canção na íntegra, acessar: 〈https://soundcloud.com/joaoleopoldo/01-me-lembra-muitopink-floyd $>$.
} 
de passarmos aos elementos que integram os aspectos linguísticos aos musicais, consideraremos primeiramente a sua letra.

\begin{tabular}{|c|}
\hline $\begin{array}{c}\text { Me lembra muito Pink Floyd } \\
\text { Artista: João Leopoldo } \\
\text { Disco: Cabeça Madura (2010) }\end{array}$ \\
$\begin{array}{c}\text { 1. Pense bem. } \\
\text { 2. Isso pode parecer com algo que você já ouviu. } \\
\text { 3. Me lembra muito Pink Floyd. } \\
\text { 4. Mas se faz diferente na forma de tocar. } \\
\text { 5. Calma. Eu sei. } \\
\text { 6. É complicado mas eu posso explicar. } \\
\text { 7. (Bom, então explica. Não fica enrolando.) } \\
\text { Eu não tinha algo certo (todo mundo tem) a dizer. } \\
\text { 9. (Eu gosto do coral que entra nessa parte.) } \\
\text { 10. E percebi que a sua ótica eu poderia mudar. } \\
\text { 11. E fazer desta melodia conhecida } \\
\text { 12. Algo diferente pra se escutar. }\end{array}$ \\
\hline
\end{tabular}

Como podemos notar, essa canção é curta. Nesta transcrição, ela possui 12 versos. Dizemos isso, pois no encarte não há a sua letra e, a depender dos elementos da melodia (depreendidos pelos ecos da gravação e de outras vozes), imaginamos que podemos aumentar essa transcrição. Decidimos por contemplar aqui a letra cantada numa versão ao vivo captada e divulgada na internet ${ }^{5}$. Deixamos os versos que não são cantados na versão ao vivo entre parênteses para marcar tais diferenças.

Ao considerar apenas a letra desta canção, é possível notar que ela se inicia marcando o contato entre o enunciador (voz principal da música) com um enunciatário. O "Pense bem" inicial assume uma função fática (JAKOBSON, 1969) que busca estabelecer um canal comunicativo entre remetente e destinatários (em termo jakobsonianos). Após esse primeiro contato, o enunciador antecipa as impressões que seu ouvinte/interlocutor pode ter, pois menciona que essa canção pode se parecer com alguma outra canção. Aos ouvidos do próprio enunciador, ela lhe "lembra muito Pink Floyd", mas é tocada de outra forma. Dessa maneira, se a canção de João Leopoldo for tratada apenas como letra de música, à parte ao material sonoro (como comumente é feito com outras canções), ela não fará o mesmo sentido quando integrada ao material

5 O vídeo está disponível em: 〈https://vimeo.com/63199647〉. 
audível, uma vez que o material sonoro, especialmente nessa canção, é parte integrante da significação global da canção - o ouvinte ouve uma coisa, mas que - se ele considerar pelo título da canção - não soa como o esperado (o título 'promete' algo que remete a Pink Floyd, mas soa como Imagine). O "truque” da canção se resguarda nisso: prometer - na forma escrita/letra cantada - uma coisa ao ouvinte, mas que - na melodia - soa diferentemente do prometido. Se consideradas as partes separadamente, a canção não faz o sentido que se propõe a fazer, ou melhor, a produção de sentido da canção fica comprometida por não ser considerada a partir das suas características multimodais.

Nos versos seguintes (5 e 6), fica evidente o predomínio da função metalinguística ${ }^{6}$ da canção, pois ele pede "calma" e anuncia que vai explicar porque a música parece uma canção da banda inglesa, mas realmente não é. O enunciador, por meio do 'calma', antecipa a reação do ouvinte logo após ele ouvir uma coisa esperando por outra. Ele, o enunciador, sabe que não se trata de Pink Floyd, mas de John Lennon, e promete explicar adiante. Basicamente, sua explicação desbanca para o fato de o enunciador não estar "inspirado" ("Não tinha algo certo a dizer") e notar que ele poderia transformar uma "melodia conhecida" em "algo diferente pra se escutar" (e, dessa forma, mudar a ótica do ouvinte). A problemática da canção é, sumariamente, causar o estranhamento no ouvinte e tentar explicar suas razões de produção. O enunciador muda a ótica do ouvinte ao mostrar que nem tudo é o que parece ser. É uma tentativa de rompimento com o que é certo, esperado, conhecido. Para tanto, ele usa dois elementos provavelmente familiares ao ouvinte ${ }^{7}$ : 1) título da canção e o verso 3 - dois elementos do âmbito escrito (se considerado como letra de música) que remetem à Pink Floyd; 2) melodia da canção Imagine - uma das canções mais conhecidas de John Lennon. Aqui, o enunciador parte de elementos verbais que, ao se encontrarem com o sonoro (melodia), 'não combinam', e acabam se tornando algo novo, ou seja, a canção que ele cria - que não se trata nem de Pink Floyd, nem de Beatles.

Notem que a análise da letra não nos leva a interpretações que ultrapassam a identificação de funções de linguagem predominantes em cada parte da canção. Não

6 Por mais que estejamos utilizando alguns aspectos das funções de linguagem (de inspiração jakobsoniana) em nossa análise, é preciso mencionar que, em realidade, a produção de sentido da canção só se efetiva se não se nos limitarmos unicamente às funções. Em suma, ao utilizar esse arcabouço teórico, buscamos mostrar seus limites.

7 Aqui se pensa na canção como algo inerentemente duplo, ou seja, é material sonoro e material verbal (escrito e/ou oral). Canção: gênero híbrido, de caráter intersemiótico; conjugação da linguagem verbal e musical (COSTA, 2007). 
estamos argumentando que tais aspectos não sejam importantes. Pelo contrário, nossa argumentação aponta para o fato de que tais aspectos de natureza linguística ganham interpretações mais "ricas" se considerarmos os elementos linguísticos e musicais da canção. Para fazer isso, analisaremos a canção interpretada no vídeo de divulgação da internet.

Para ilustrar a nossa análise sobre as questões multimodais da canção, desenvolvemos um diagrama que ilustra os momentos de tensão e relaxamento possíveis de se identificar. Nosso diagrama é dividido em três níveis: melodia, harmonia e letra. Os pontos de tensão e relaxamento são ilustrados pela aproximação entre as linhas da melodia e da harmonia. Ainda, a leitura do diagrama se dá da esquerda para a direita, seguindo os números de 1 a 16.

\begin{tabular}{|c|c|c|c|c|}
\hline Melodia & Não remete à Imagine & & & \\
\hline Harmonia & \multicolumn{2}{|c|}{ Remete à Imagine } & \multirow{2}{*}{ Não remete à Imagine } & Cadência "coringa" \\
\hline Letra & $\begin{array}{l}1 \\
\text { Pense bem. }\end{array}$ & $\begin{array}{l}2 \\
\text { Isso pode parecer }\end{array}$ & & $\begin{array}{l}4 \\
\text { viu. Me lembra } \\
\text { muito Pink Floyd. }\end{array}$ \\
\hline \multirow[t]{2}{*}{ Melodia } & \multicolumn{4}{|l|}{ Não remete à Imagine } \\
\hline & Cadência "coringa" & \multirow{2}{*}{\multicolumn{2}{|c|}{$\begin{array}{c}\text { Cadência "coringa" } \\
\end{array}$}} & \\
\hline Harmonia & Não remete à Imagine & & & Sugestão de Imagine \\
\hline Letra & $\begin{array}{l}5 \\
\text { Mas se faz diferente na } \\
\text { forma de tocar. }\end{array}$ & $\begin{array}{l}6 \\
\text { Calma. Eu sei. }\end{array}$ & $\begin{array}{l}7 \\
\text { É complicado mas eu } \\
\text { posso expli- }\end{array}$ & $\begin{array}{l}8 \\
\text { car. }\end{array}$ \\
\hline \multirow[t]{2}{*}{ Melodia } & \multicolumn{4}{|l|}{ Não remete à Imagine } \\
\hline & & Fá Menor & Dó Maior & Fá Menor \\
\hline Harmonia & Preparação para outra parte & Não remete à Imagine & $\ldots \ldots$ & $\ldots \ldots$ \\
\hline Letra & 9 & $\begin{array}{l}10 \\
\text { Eu não tinha algo } \\
\text { certo a di- }\end{array}$ & $\begin{array}{l}11 \\
\text { zer. }\end{array}$ & $\begin{array}{l}12 \\
\text { E percebi que a sua } \\
\text { ótica eu poderia mu- }\end{array}$ \\
\hline \multirow[t]{2}{*}{ Melodia } & Não remete à Imagine & & & \\
\hline & Cadência "coringa" & & & \\
\hline Harmonia & $\cdots \cdots$ & Tensão & \multicolumn{2}{|c|}{ Preparação para final: Tensão momentânea $\rightarrow$ resolução } \\
\hline Letra & $\begin{array}{l}13 \\
\text { dar. E fazer desta } \\
\text { melodia }\end{array}$ & $\begin{array}{l}14 \\
\text { conhecida }\end{array}$ & $\begin{array}{l}15 \\
\text { Algo diferente }\end{array}$ & $\begin{array}{l}16 \\
\text { pra se escutar. }\end{array}$ \\
\hline
\end{tabular}

Figura 1 - Diagrama analítico em três níveis: melodia, harmonia e letra. 
Esse vídeo inicia com a performance baseada em piano e voz da canção "A aranha e o cílios”. Nessa música (originalmente gravada no disco de 2008, “Acostumando os ouvidos"), é narrada a história de uma aranha que se apaixona pelos cílios de um olho. Após esse diálogo surreal, o vídeo inicia com uma introdução no piano que sugere a interpretação da famosa música Imagine, de John Lennon (do álbum homônimo de 1971). Contudo, essa introdução não é tocada na íntegra. João Leopoldo inicia a introdução tocando um compasso no acorde dó maior e um no acorde em fá maior. Cada vez que a melodia ascendente vai ser tocada no fim do segundo compasso da introdução, ela é interrompida. As hesitações e expressões faciais apresentadas no vídeo não deixam dúvidas de que ele está sugerindo uma canção que a maioria das pessoas deve conhecer. Esse movimento de sugestão ocorre duas vezes antes de iniciar a voz na canção. É também o corpo (imagético e performático, por ser parte do vídeo) componente da significação multimodal do texto aqui escolhido.

Após essa introdução instrumental, a canção inicia a sua parte cantada. Já nesse começo ocorre um distanciamento entre a melodia e a harmonia, uma vez que é possível identificar entre os compassos 1 e 2 (representados pela contagem numérica e separados por barras verticais) que a forma cantada não remete à canção Imagine de John Lennon, enquanto a harmonia (o acompanhamento pelos acordes tocados no piano) remetem à canção do ex-Beatle. Esse distanciamento inicial promove uma certa tensão no ouvinte. Tal tensão está representada pelo distanciamento entre a linha simples contínua da melodia e a linha dupla contínua da harmonia. Ao se iniciar o compasso 3, há uma alteração na progressão dos acordes. Inicia-se um acorde de Fá Menor, quebrando a progressão de Imagine (que é construída basicamente sobre a alternância entre Dó Maior e Fá Maior, tal como apresentado na introdução do vídeo). Isso faz com que tanto melodia quanto harmonia sejam desconhecidas e, consequentemente, novas ao ouvinte, que irá experienciar a canção sem tensões promovidas pelo reconhecimento de outras formas musicais. Contudo, já nos compassos 4 e 5, a tensão surge novamente pelo desencontro entre a letra da canção, pois tanto melodia quanto harmonia não remetem à Imagine e a letra sugere que se trata de uma canção conhecida que pode parecer alguma da banda britânica Pink Floyd (distanciamento entre as linhas melódica e da letra). Essa tensão só se desfaz entre os compassos 6 e 7, quando a letra pede "calma" ao ouvinte e sugere uma explicação sobre a canção. 
Em seguida, nos compassos 8 e 9, a tensão aparece como uma preparação para algo inesperado, sugerindo um certo mistério para a explicação mencionada nos compassos anteriores. Mais uma vez, mantivemos as linhas da melodia e harmonia distanciadas. O relaxamento surge, por sua vez, entre os compassos 10 e 13, pois tanto melodia quanto harmonia não são de Imagine. A tensão só surge novamente quando, no compasso 14, a letra sugere que o enunciador quer transformar a melodia conhecida (que não é a de Imagine) em "diferente para se escutar". A tensão entre esses compassos 15 e 16 se mantém constante para ocorrer a preparação e a resolução da canção.

Com esse diagrama, tentamos simplificar questões relacionadas à notação musical e mostrar que é possível ilustrar para os alunos que uma canção pode apresentar níveis que se relacionam e promovem efeitos de sentido. Essa análise não é única e tampouco está totalmente acabada. Ela aponta para maneiras de tratar de questões multimodais em sala de aula. Imaginamos que trabalhar graficamente com as linhas de aproximação (relaxamento) e distanciamento (tensão) pode ser uma alternativa interessante para trabalhar questões musicais sem ser excessivamente técnico. Vale ressaltar, ainda, que uma quarta linha poderia ser inserida sugerindo aspectos visuais do vídeo, proporcionados pelas hesitações e outros aspectos interpretativos.

Em suma, como podemos ver, a canção, desde seu título, sugere que há algo que se assemelha às canções da banda britânica Pink Floyd. Contudo, o que presenciamos durante a sua interpretação é um diálogo entre a letra da canção e a harmonia de Imagine, de John Lennon. Certamente, poderíamos pensar que a "aparição" da canção do ex-Beatle seja um caso de citação, pois o artista toca os mesmos acordes e melodias de Imagine durante a introdução e no início da parte cantada da canção. Contudo, considerá-la apenas como citação pode ser demasiadamente redutor. Como mostramos acima, letra e harmonia percorrem direções opostas, como se estivessem brincando com o que o ouvinte já conhece (harmonia) e como informações novas (a letra da música), criando os momentos de tensão e relaxamento. São dois escopos diferentes funcionando para a criação de sentidos, proporcionando a multimodalidade da canção. Grosso modo, podemos dizer que a canção de João Leopoldo é outra canção, porque não é Imagine e tampouco alguma do Pink Floyd. É o "algo diferente pra se escutar" que o enunciador se propõe a fazer. 


\section{Considerações pontuais}

O objetivo geral desse texto é argumentar a favor da introdução de outros textos na sala de aula. Assumindo uma perspectiva baseada nos multiletramentos, decidimos apresentar como a canção pode ser objeto essencialmente multimodal e que tais aspectos linguísticos, musicais e visuais produzem sentidos.

Àqueles que podem achar que a análise de canções pode ser notadamente complicada e extremamente técnica, é preciso mencionar que aqui foram utilizadas nomenclaturas típicas do âmbito musical. Contudo, tais nomenclaturas não são obrigatórias. Trabalhar com a percepção (tanto na identificação de melodias e harmonias quanto na diferenciação de partes tensas e "relaxadas") é suficiente para promover uma leitura que busque a produção de sentidos ao se contemplar a produção artística. Por exemplo, Rosenblum (2010) mostra que, ao contrário do que o senso comum postula, os seres humanos têm capacidades musicais que podem ser utilizadas amplamente. Em estudos de laboratório, o autor verifica que os participantes da pesquisa possuíam afinação perfeita ou muito próxima das originais quando solicitados a cantarem de memória alguma canção conhecida, tal como "Parabéns pra você". Somase a isso que as pessoas também reconhecem o ritmo e reproduzem os ritmos originais de tais canções, de modo que conseguiam manter o beat certo por quase todo o processo de cantar. Por sua vez, tais estudos mostraram que a dificuldade da maioria das pessoas não é em reconhecer ou cantar afinadamente. A dificuldade está em cantar com afinação e dentro do ritmo quando está sendo acompanhado por algum instrumento.

Argumentamos que tais capacidades devem ser exploradas em sala de aula, de modo que os alunos podem ser solicitados a reconhecer e identificar mais esses elementos musicais que promovem outras leituras e produzem sentidos. O professor não precisa ser especialista em música para poder trabalhar canções em sala de aula, mas deve se atentar aos elementos que as compõem e como tais elementos contribuem para a formação de sentidos de maneira a proporcionar letramentos diferentes no contexto escolar. Kleiman (2005, p. 52-53) afirma que

Ao contrário do superprofessor, esse agente [de letramento] não precisa saber tudo sobre a língua escrita, sobre as linguagens nãoverbais, sobre as novas práticas sociais emergentes, porque, ao se engajar em práticas de letramento, estará engajado numa atividade 
colaborativa em que todos têm algo com que contribuir e todos têm algo a aprender.

Por fim, cabe mencionar que levar a sério a multimodalidade implica em trabalhos multidisciplinares e, acima de tudo, assumir que há outros textos que podem ser levados para dentro da sala de aula. Essa discussão ainda precisa ser ampliada. Um bom exemplo é a pesquisa de Sierakowski (2012), na qual a pesquisadora propõe que a dita literatura de massa pode sim formar leitores críticos. Cabe apenas à escola aceitar a introdução de tais textos no âmbito escolar, não como deturpações do cânone, mas como elementos importantes no processo de formação da identidade leitora - assim como a aceitação de textos multimodais.

NISHIDA, Gustavo; SIERAKOWSKI, Ana Paula de Castro. For other texts in the classroom: Me lembra muito Pink Floyd, by João Leopoldo. Revista do Gel, São Paulo, v. 13, n. 3, p. 203-218, 2016.

Abstract: This work aims at arguing for the inclusion of other texts in Portuguese language classroom. Our argumentation points to an expansion in the concept of reading and to the use of other discursive genres in order to form readers. To do so, we assume that, in order to bring multimodal literacies (ROJO, 2009) to the classroom, it is necessary that other texts (multimodal and vernacular) be analyzed and included in the educational context. To this end, we are going to use the song Me lembra muito Pink Floyd, by João Leopoldo, the composer from São Paulo state (song from the album Cabeça Madura, 2010) to illustrate how multimodality can be part of the Portuguese language classroom. Basically, the song meaning production is made by metalinguistic elements of the lyrics that suggest that this song might look like some song by Pink Floyd. However, the musical elements are not from the British band, they are from Imagine, by John Lennon. Overall, it is the integration of linguistic and musical elements that promote the production of meaning of the song.

Keywords: Multimodality. Popular song. Vernacular literacy.

Submetido em: 03/04/2016.

Aceito em: 16/06/2016. 


\section{Referências}

ANTUNES, I. Aula de português. São Paulo: Parábola, 2001.

BAKHTIN, M. Marxismo e filosofia da linguagem. São Paulo: Hucitec, 1992.

BENTES, A. C. A lingüística textual. In: MUSSAlIN, F.; BENTES, A. C. (Org.). Introdução à Linguística. São Paulo: Cortez, 2001.

BRASIL. Ministério da Educação; Secretaria de Educação Fundamental. Parâmetros Curriculares Nacionais: Língua Portuguesa. Brasília: MEC/SEEF, 1997.

CLÜVER, C. Inter Textus / Inter Artes / Inter Media. Aletria: revista de estudos de literatura. 2007. p. 11-41.

CORACCINI, M. J. Concepções de leitura na (pós) modernidade. In: CARVALHO, R. C.; LIMA, P. (Org.). Leitura: múltiplos olhares. Campinas: Mercado de Letras, 2003.

COSTA. N. B. da. As letras e a letra: o gênero canção na mídia literária. In: DIONÍSIO, A. P. et al. (Org.). Gêneros textuais e ensino. 5. ed. Rio de Janeiro: Lucerna, 2007.

GERALDI, J. W. (Org.). O texto em sala de aula: leitura e produção. Cascavel: ASSOESTE, 1984.

JAKOBSON, R. Linguística e poética. In: Linguística e comunicação. São Paulo: Cultrix, 1969. p. 118-132.

KLEIMAN, A. B. Preciso "ensinar" o letramento? Não basta ensinar a ler e a escrever? Coleção Linguagem e letramento em foco: linguagem nas séries iniciais. Ministério da Educação. Cefiel/IEL. UNICAMP, 2005-2010.

KLEIMAN, A. B. Modelos de letramento e as práticas de alfabetização na escola. In: KLEIMAN, A. B. (Org.). Os significados do letramento. Campinas: Mercado das Letras, 1995. p. 15-61.

KRESS, G. Multimodality. In: COPE, B.; KALANTZIS, M. Multiliteracies. Routledge: London, 2006. p. 182-202.

MARCUSCHI, L. A. Produção Textual, análise de gênero e compreensão. São Paulo: Parábola Editorial, 2008.

NISHIDA, G. Molinos de viento: Mago de Oz, La leyenda de la Mancha e Formação de leitores. In: Anais do Primeiro congresso Internacional de Estudos do Rock. Cascavel, 2013.

PARANÁ. Secretaria de Estado da Educação; Superintendência da Educação. Diretrizes Curriculares da Educação Básica: Língua Portuguesa. Curitiba: SEED/DEE, 2008. 
ROJO, R. Letramentos múltiplos, escola e inclusão social. São Paulo: Parábola, 2009.

ROSENBLUM, L. See what I'm saying: the extraordinary powers of our five senses. New York: Norton \& Company, 2010.

SIERAKOWSKI, A. P. C. Literatura de massa e formação de leitor: o letramento de receptores da saga Crepúsculo do papel às telas. 2012. $181 \mathrm{f}$. Dissertação (Mestrado em Letras) - Universidade Estadual de Maringá, Maringá. 2012. 